\title{
SITE OF EMETIC ACTION OF ORAL COPPER SULFATE IN DOGS (II) IMPORTANCE OF LOWER DUODENUM
}

\author{
Noriyasu KAYASHIMA, Makoto IWASAKI* and Toyoaki HAYAMA \\ Laboratory of Veterinary Pharmacology, Faculty of Agriculture, \\ Tokyo Noko University, Musashi-fuchu, Tokyo 183, Japan
}

Accepted April 17, 1978

\begin{abstract}
Sensitivitics of the stomach and duodenum to oral copper sulfate emesis were comparcd in dogs. 1) Dogs equipped with a stainless steel cannula in the middle of the duodenum were challenged to the oral threshold emetic dose of copper sulfate administcred by a gastric tube. When the cannulas were opened, the oral thresholds were not effective to elicit vomiting in the most cases $(1 / 13)$. Fairly rapid and high rate recoveries of copper through the open cannula were noted. Wilh the closed cannulas, the thresholds were highly effective $(16 / 16)$. 2) In the dogs with a cannula at the upper part of the jejunum, the oral threshold doses were always effective whether the canula was opened $(9 / 9)$ or closed (11/11). Recovery rates of copper from the cannula were usually poor. 3) The oral thresholds administered into the proximal end or the middle of the duodenum through a PVC tubing were equally effective. 4) Although copper sulfate might irritate the stomach and upper duodenum to evoke vomiting, these results suggested a higher sensitivity of the lower duodenum.
\end{abstract}

In a previous paper (1), the emetic thresholds of copper sulfate administered locally into the various portions of the gastrointestinal tract of dog were measured to determine the site of emetic action of the salt. We concluded that copper sulfate might act on the pyloric antrum and/or duodenum. However, this conclusion was based on the data under a stressed condition after a major operation as pointed out in the paper. Differences of the intraluminal environment between the isolated lumen and normal lumen werc also a subject to require reconsideration.

The present study was carried out to compare the sensitivities of the stomach and duodenum to copper sulfate under a more physiological condition than the previous study.

\section{MATERIALS AND METHODS}

Animals

More than 20 healthy mongrel dogs, selected by the previously described procedure (1), were kept under a constant condition $\left(22+2^{\circ} \mathrm{C}, 50-60 \%\right.$ humidity, 10 air changes $\left./ \mathrm{hr}\right)$ throughout the quarantine and experiments. The vomiting experiment was carried out in the animal quarters once a wock at most. Sometimes, a two week rest was necessary to prevent the development of anemia.

\section{Determination of threshold}

The method determining the threshold of oral copper sulfate emesis was described in

* Present Address: Laboratory of Pharmacology, Toxicology Division, The Institute of Environmental Toxicology, Kodaira-shi, Tokyo 187, Japan 
the previous paper (1). Copper sulfate was dissolved in $40 \mathrm{ml}$ and given via gastric tube. The threshold obtained preoperatively was confirmed postoperatively.

For the intracatheter instillation, a dose of copper sulfate was dissolved in $10 \mathrm{ml}$ of water and administered into the intestine through a PVC tubing. To prepare the acidfied copper sulfate solution, the salt was dissolved in $10 \mathrm{ml}$ of $0.1 \mathrm{~N} \mathrm{HCl}$ solution (pH 1).

\section{Operations}

The stainless steel cannula used for the intestinal cannulation was small in size, otherwise the same as a gastric cannula used commonly. A mid-duodenal cannula was set, like a Thomas type cannula, on the opposite side of the opening of the main pancreatic duct and protruded from the right side of the abdominal wall. An upper jejunal cannula was set at the 3 to $5 \mathrm{~cm}$ below the end of the duodenojejunal flexure and protruded out of the left side of the wall (Fig. 1). The cutaneous stab wound, through which a cannula was brought out, was made at about $2 \mathrm{~cm}$ ventrally from the normal position of the intestine, so that the passing content could be withdrawn through the cannula during an open cannula experiment.

For the direct infusion of copper sulfate into the duodenum, two PVC tubings were set to the just below the pylorus and the opposite side of the opening of the main pancreatic duct and pulled out of the body at the shoulder through the subcutaneous space (Fig. 1).

Only one cannula or two catheters was usually placed in an animal to lessen the operative stress. Dogs were quarantined for at least 2 weeks of rest, postoperatively.

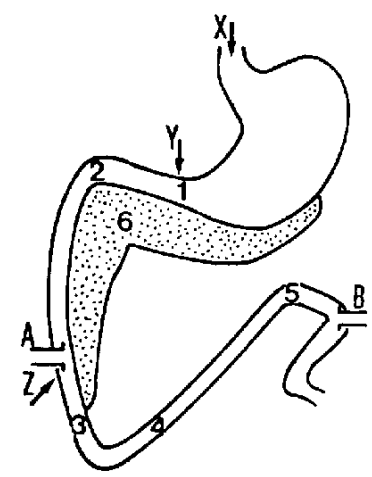

FIG. 1. Operations and route of administration in the text.

1 pylorus

2 cranial duodenal flexure

3-4 caudal duodenal flexure

5 duodenojejunal flexure

6 pancreas

A mid-duodenal cannula

B upper jejunal cannula

$X$ oral administration

$Y$ pyloroduodenal catheter

$\mathrm{Z}$ mid-duodenal catheter

$\mathrm{Y}-\mathrm{A}$ upper duodenum

Z-B lower duodenum

\section{Determination of copper}

When the cannula was opened during vomiting experiment, leakage out of the cannula was collected every $5 \mathrm{~min}$ for $30 \mathrm{~min}$. If dog vomited, collection was discontinued. The collected sample was measured for volume, placed into a Kjeldahl flask, concentrated sulfric acid was added and the preparation boiled until the mixture appeared clean. Concentration of copper was measured by an atomic absorption method.

\section{RESULTS}

\section{Opening of the intestinal cannula}

Results obtained are summarized in Table 1. When the mid-duodenal cannulas were opened, the oral threshold doses were not effective in the most cases, whereas the thresholds 


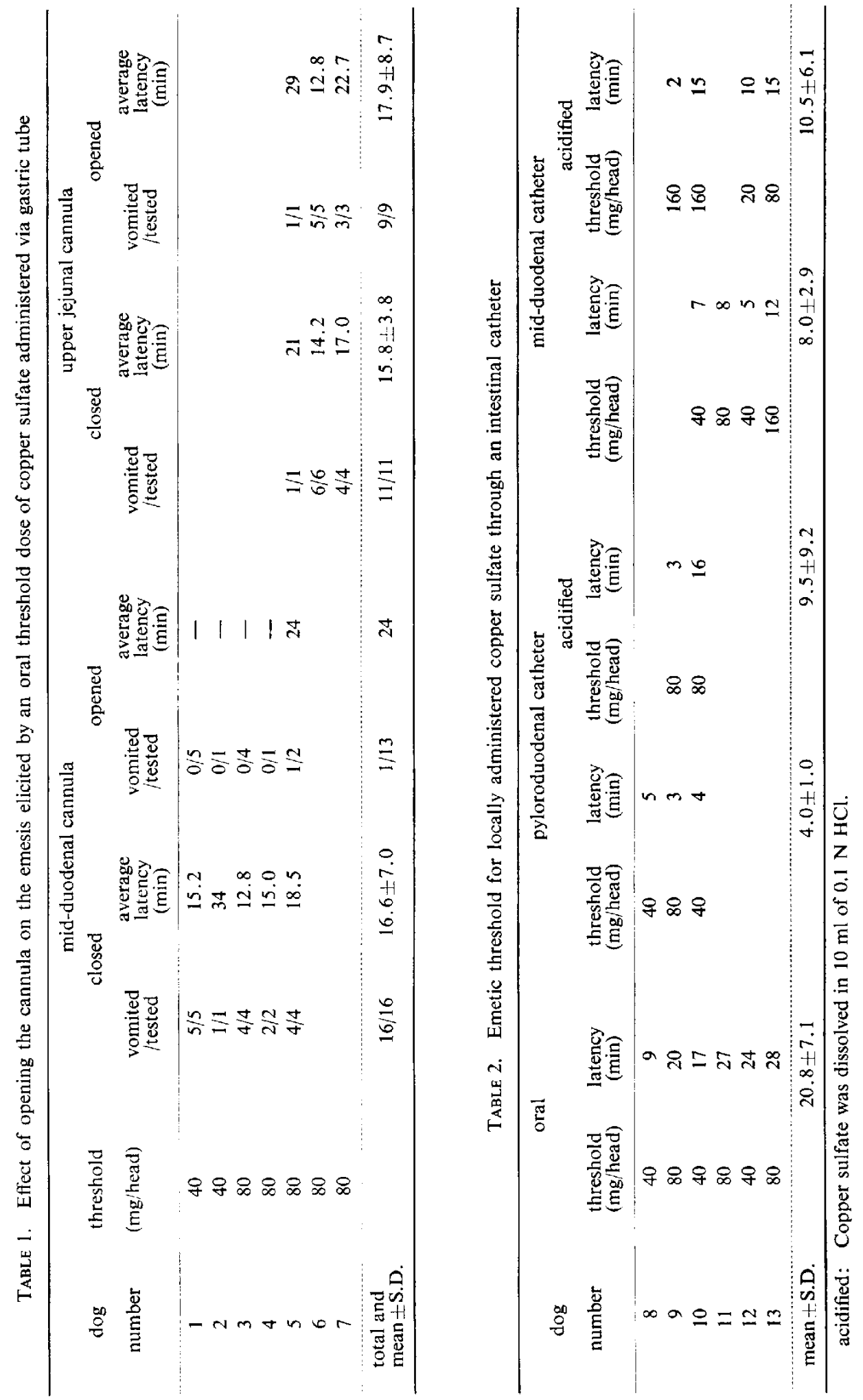




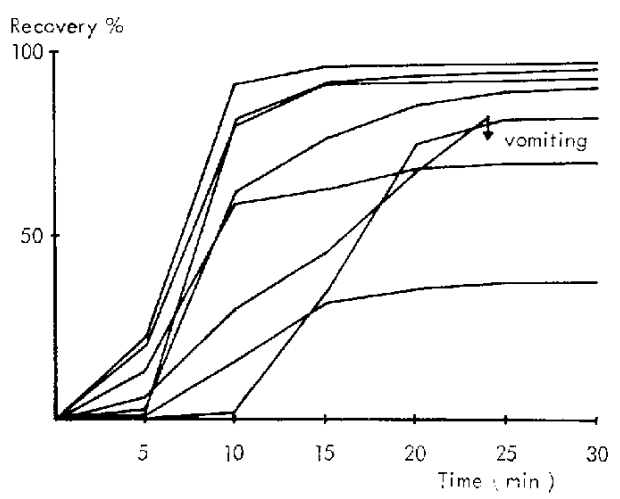

FIG. 2. Recovery of orally administered copper through the mid-duodenal cannula.

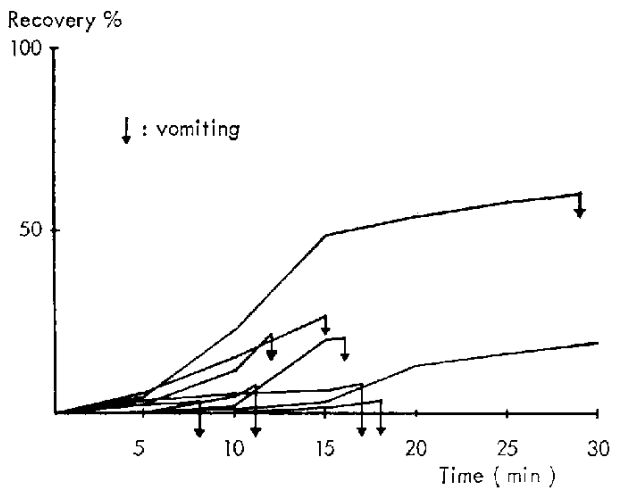

FIG. 3. Rccovery of orally administered copper through the upper jejunal cannula.

were always effective in the cannula closed dogs. No effect of opening of the upper jejunal cannulat was observed.

\section{Recovery of copper through the canmula}

Recoveries of copper through the mid-duodenal cannula are illustrated in Fig. 2. In most cases, a high recovery rate was achieved within 10 through $15 \mathrm{~min}$. The $\mathrm{pH}$ of the withdrawn fluid samples ranged from 3.4 to 7.0.

Fig. 3 shows recoveries from the upper jejunal cannula. Slow and poor recoveries were observed.

\section{Intestinal infusion}

The oral threshold dose was dissolved in $10 \mathrm{ml}$ of water and injected into the duodenum through the PVC tubing. Results are summarized in Table 2. When the salt solution was injected into the pyloric end, the oral thresholds elicited vomiting in all 3 cases. The second trials with $1 / 2$ of the oral threshold were not effective. Injections into the midduodenum of the oral thresholds were effective in 3 out of 4 cases. Another dog vomited with double the threshold. Shorter latencies were noted in all the cases. Acidified solution was also injected into the duodenum to determine a threshold, without obtaining a constant result.

In all dogs, postoperative oral thresholds were the same as preoperative ones.

\section{DISCUSSION}

Table 3 shows the gastrointestinal portions contacted with copper sulfate in this experiments. The orally administered copper of the threshold dose in the open mid-duodenal cannula dog passed through the stomach and upper duodenum without evoking vomiting, while the same dose in the other cannula dogs passed through the stomach and whole duodenum and elicited vomiting. The oral thresholds injected into the proximal end and middle of the duodenum were equally effective. These results suggested that the lower duodenum might have a higher sensitivity than the stomach and upper duodenum.

The duodenum was divided in to two portions, upper and lower. The upper duodenum 
TABLE 3. Gastrointestinal portions exposed to copper sulfate in the text

\begin{tabular}{lccccc}
\hline \multicolumn{1}{c}{ preparation } & $\begin{array}{c}\text { route of } \\
\text { administration }\end{array}$ & stomach & $\begin{array}{c}\text { upper } \\
\text { duodenum }\end{array}$ & $\begin{array}{c}\text { lower } \\
\text { duodenum }\end{array}$ & $\begin{array}{c}\text { rest of } \\
\text { Gl tract }\end{array}$ \\
\hline mid-duodenal cannula, opened & intragestric & $\exp$ & $\exp$ & - & - \\
mid-duodenal cannula, closed & do & $\exp$ & $\exp$ & $\exp$ & $\exp$ \\
upper jejunal cannula, opened & do & $\exp$ & $\exp$ & $\exp$ & - \\
upper jejunal cannula, closed & do & $\exp$ & $\exp$ & $\exp$ & $\exp$ \\
pyloroduodenal catheter & intracatheter & - & $\exp$ & $\exp$ & $\exp$ \\
mid-duodenal catheter & do & - & - & $\exp$ & $\exp$ \\
\hline
\end{tabular}

exp: exposed, - $\quad$ : not exposed

in the text refers to the portion from the pylorus to the opening of the main pancreatic duct. The lower refers to the rest of the duodenum and the first $5 \mathrm{~cm}$ of the jejunum, since setting a cannula at the end of the duodenum is technically difficult (Fig. 1).

We had considered that copper in the acid solution was not so effective as copper in the neutral solution, because the $\mathrm{pH}$ of the contents in the stomach and upper duodenum was about 2 , whereas in the lower duodenum it was about 6 . Determinations of threshold to the acidified copper sulfate injected into the duodenum were carried out to check the possibility, but a constant result to support the speculation was not obtained.

There is a possibility that a high concentration of copper sulfate in the stomach may irritate the tissue to cause a pylorospasm, delay the emptying, and remain in the stomach long enough to elicit vomiting. Although we have few data (unpublished) in which $160 \mathrm{mg}$ of copper sulfate dissolved in $10 \mathrm{ml}$ was administered by mouth and recovered from the midduodenal cannula fairly rapidly (dog did vomit), the possibility seemed unlikely up to this concentration.

\section{REFERENCE}

1) Kayashima, N., Tanaks, M., Iwasaki, M. and Hayama, T.: Site of emelic action of oral copper sulfate in dogs (I) Thresholds of various portions of gastrointestinal tract to locally applied copper sulfate. Japan. J. Pharmacol. 98, 775-781 (1978) 